\title{
Correlates of the Oral Language Performance of Sixth Grade Students Exposed to Multilingual Instruction in Private Schools in Tacloban City
}

\author{
Ma. Rebecca A. Abayan* \\ a abayanmarebecca@gmail.com \\ Leyte Normal University, Tacloban City 6500, Philippines
}

\begin{abstract}
Multilingual instruction is a common practice nowadays wherein various languages are used as medium of instruction. This descriptive study sought to determine the oral language performance of grade six students enrolled in trilingual instruction in some private schools in Tacloban City, Philippines. Primarily, it aimed to find out the profile of the students in terms of some student, home and teacher factors; determine whether there is significant correlation between these factors; determine if they correlate with oral language performance; and, identify the most important predictor that may influence oral language performance. A total of 37 respondents from the 115 sample population drawn through simple random sampling, the respondents were asked to answer questionnaires and were given oral proficiency tests in English, Filipino and Chinese. The results revealed that the students were labelled as Limited Speakers in English and Non-Speakers in both Filipino and Chinese. Their oral language performance was influenced by the students' attitude towards Filipino, their motivational orientation, the kind of school enrolled in, as well as the teachers' age and years of teaching experience. The kind of school enrolled in found to be a significant predictor of oral language performance of the students.
\end{abstract}

Keywords: oral language performance; trilingual instruction; descriptive-correlational

\section{Introduction}

\subsection{Background and rationale}

Language is defined as a systematic means of communicating by the use of sounds and conventional symbols. It is used in giving information, expressing feelings and emotions, establishing rapport, exercising authority and an identity marker (Stahlke, 2002). Nowadays, speaking two or more languages is already a common phenomenon all over the world. People tend to become bilingual, trilingual or multilingual as the case may be in order to understand and be able to communicate with others in a language that other people can understand and speak. Ryu (2019) points out that, in most instances, people tend to become bilingual or multilingual by using or combining two or more languages in order to be able to communicate actively and effectively with others in various situations.

It has been estimated that some sixty percent of today's world population is multilingual. Hence, 
bilingualism and multilingualism are the norm rather than the exception from both a contemporary and a historical point of view (Harris \& McGhee-Nelson, 1992). Current studies show that multilingualism continues to spread around the world caused by the changes in the economy, politics, culture, and education. Multilingualism is likewise considered to be a leading factor in the success of the business and professional spheres (Kulsariyeva, Iskakova, \& Tajiyeva, 2017).

In the General Assembly in 1999 the UNESCO adopted the $12^{\text {th }}$ resolution authorizing the term "Multilingual Education" which involves the use of at least three languages in education, namely: the mother tongue (the first language of the learned), regional language, and the international language. This trilingual standard was described in the installation document of UNESCO in 2002 as "Education in a multilingual world."

The Philippines has enacted a national policy institutionalizing and enacting into law "the MotherTongue-Based Multilingual Education (MTB-MLE) in mainstream formal education through Department of Education (DepEd) Order No. 74, which later broadened its coverage when "Enhanced basic Education Act of 2013" was signed by President Benigno Aquino III (Tupaz, 2016).

In the school context, the use of more than one language is required as language of communication and instruction. As media of instruction, bilingualism and multilingualism is already a common reality. For most schools, bilingualism is practiced where English and Filipino are used in teaching the concepts in the different subject areas.

With the promulgation of the MTBMLE or Mother-Tongue-Based Multilingual Education, trilingualism is emphasized. While Chinese schools, the Chinese grammar and literature and Chinese Communication included in their curriculum as part of the school's objective in the propagation of the Chinese Heritage.

The use of language for instruction is equally important for communication. One of the main objectives of the English, Filipino and Chinese subjects is to develop fluency and proficiency in performing the different language functions. One of which is communication. One's ability to understand and communicate effectively using the target languages would require vast knowledge of the linguistic and nonlinguistic structures of the languages.

Does simultaneous language learning and acquisition of three languages contribute to better oral language performance in English? Does it hamper one's ability from achieving language proficiency in one, two or three languages used simultaneously? What factors greatly affect their oral language performance? What are some predictors of good language performance? These questions brought about the conceptualization of this study.

\subsection{Framework of the study}

This study is anchored upon the language learning theory believed to have some bearing on the problem ventured into.

The Acculturation Model of Schumann (1986) states that the degree to which a person acculturates himself to the target language will determine how fast he/she will acquire a certain language. Thus, the more that a person assimilates himself with the target language, the faster and the more successful will learning and language acquisition be.

On this premise, learning and language acquisition is rapid if social distance is lesser, and is slow if the social distance is greater Hence, when one is immersed in the culture of the communities that speak the language, he develops higher level of proficiency for being exposed to the language. This provides the language learner an authentic and natural learning environment wherein one receives authentic inputs about the language and which in turn provides the learner the chance to communicate by speaking the target language. 
In the classroom setting, the learners' degree of exposure to the languages used as media of instruction can bring about certain level of proficiency in the oral language performance of the learner. Likewise, certain underlying factors such as the home, teacher and student factors adversely affect their oral language performance.

These factors have been classified into three groups; namely, student, home, and teacher factors. The student variables to be studied include language preference, media preference, study habits, attitude towards English, attitude towards Filipino, attitude towards Chinese, motivational orientation, length of exposure to the three languages, and the kind of school enrolled in. The home factors include language spoken at home, educational materials at home, ethnic background, and attitude of parents towards the three languages. The teacher factors such as age, major/specialization, educational qualification, and experience in teaching will also be studied. This study likewise aimed to find out the effects of the students' exposure to the trilingual instruction to their language performance.

The schema shows some factors that may affect the oral language performance of the grade six students who are exposed to the trilingual instruction.

Figure 1. Factors that Affect the Oral Language Performance of Students

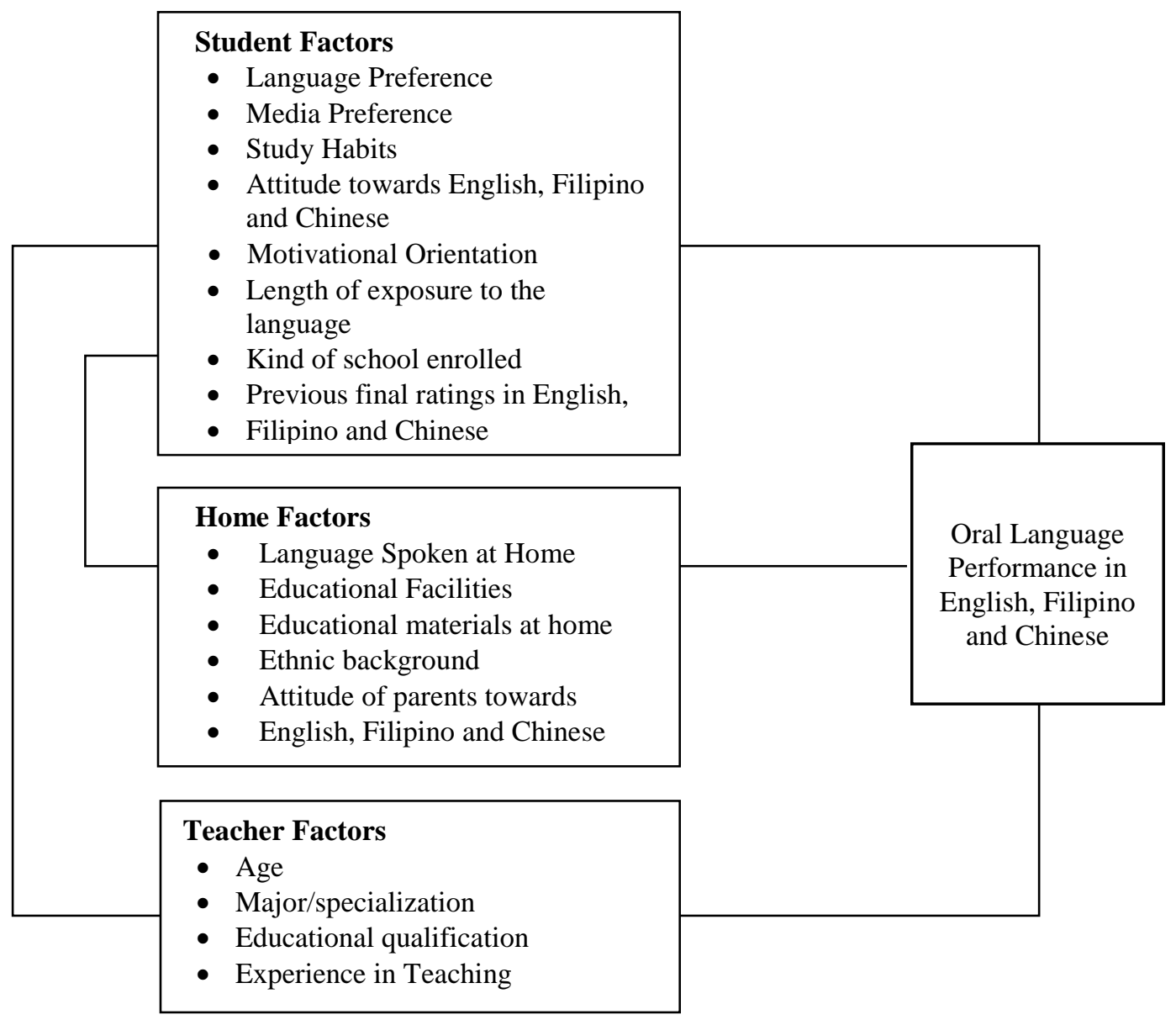




\subsection{Statement of the problem}

This study aims to find out the oral language performance of the sixth graders exposed to trilingual instruction in some private schools in Tacloban City, determine whether the student, home and teacher factors had some bearing on their performance in English, Filipino and Chinese.

Specifically, it aimed to answer the following questions:

1. What is the profile of the student respondents in terms of the following student factors?

1.1 Language preference

1.2 Media Preference

1.3 Study habits

1.4 Attitude towards English, Filipino and Chinese

1.5 Motivational Orientation

1.6 Length of exposure to the English, Filipino, and Chinese languages

1.7 Kind of school enrolled

1.8 Previous final rating I English, Filipino and Chinese

2. What is the profile of the student respondents in terms of the following home factors?

2.1 Language spoken at home

2.2 Educational Facilities

2.3 Educational materials at home

2.4 Ethnic background

2.5 Attitude of parents towards English, Filipino and Chinese

3. What is the profile of the teachers in terms of the following?

3.1 Age

3.2 Major/specialization

3.3 Educational qualification

3.4 experience in teaching

4. What is the oral language performance of the grade six students in the following?

4.1 English

4.2 Filipino

4.3 Chinese

5. Is there a significant relationship between student factors and home factors?

6. Is there a significant relationship between student factors and teacher factors?

7. Is there a significant relationship between student factors and oral language performance?

8. Is there a significant relationship between teacher factors and oral language performance?

9. Is there a significant relationship between home factors and oral language performance?

10. What is the most important predictor taken singly for student, home, and teacher factors that may influence oral language performance in English, Filipino and Chinese?

\section{Review of literature}

Various reports and findings of researches relate to this study. Charcova (2004) studied on the early foreign language education and metalinguistic development focusing on monolingual, bilingual and trilingual children in terms of their noun definition tasks. It also determined the relationship between $\mathrm{L}_{1}$ definition performance, $\mathrm{L}_{2} / \mathrm{L}_{3}$ proficiency and $\mathrm{L}_{2} / \mathrm{L}_{3}$ definition performance within bilingual and trilingual groups. Results of the study revealed that the groups of bilingual and trilingual children performed significantly better on the $\mathrm{L}_{1}$ word definition test than the group of the monolingual children. However, there 
was no significant difference between the performance of the bilingual and trilingual groups in the worddefinition tasks in $\mathrm{L}_{1}$.

In the study of De Guzman \& De Vera, they investigated the status of elementary grade pupils' English proficiency in the content of those taking separately the Mother Tongue and English but are integrated within the same curriculum year level. Results revealed that the pupils' academic performance in English, across the three groups, the pupils' academic performance in English generally registered into level of "outstanding", Very Satisfactory" and Fairly satisfactory.

The study of Lugoloobi-Nalunga (2013) investigated on whether code switching is an asset or a problem in a multilingual classroom. The results revealed that the use of several language and code switching is an asset as it has a positive impact in an English EFL/ESL teaching/learning situation in the multilingual classroom. She further recommended that teachers should allow for the pluralistic language society and permit more on the use of L1 in the English classroom.

\subsection{Research hypotheses}

This study tested the following hypotheses at 0.05 level of significance:

1. There is a significant relationship between student factors and home factors.

2. There is a significant relationship between student factors and teacher factors.

3. There is a significant relationship between student factors and oral language performance.

4. There is a significant relationship between teacher factors and oral language performance.

5. There is a significant relationship between home factors and oral language performance.

\section{Methodology}

\subsection{Subjects / respondents of the study}

Respondents of the study were the grade six students in three private schools in Tacloban City. The students come from different sections or classes selected thru stratified random sampling.

\subsection{Research instruments}

The researcher used varied instruments in order to generate important data relative to the study. These include teacher-made questionnaires, motivation orientation scale, language attitude scale, and oral proficiency test. The instruments were validated and subjected through content evaluation buy experts and were pilot tested to some sixth grade students from other institutions.

\subsection{Design and procedure}

This study utilized the descriptive-correlational method. The study was designed to establish the degree of relationships between the student factors, home and teacher factors being the independent variables; and the dependent variable, that is, the language performance of the grade six students in English, Filipino and Chinese. This study also aimed to find out if trilingual instruction significantly correlates with the language performance of the grade six students in English, Filipino and Chinese.

To gather the data needed in this study, first, letters were sent to the school principals to seek permission from them regarding the conduct of the study. Once permit was granted, the alphabetical listing of all the students in grade six were secured from the registrar's office of the different sample schools. Then a letter of communication was sent to all the respondents informing them and their parents of their preparation in the said study. 
Copies of the students' final ratings in English, Filipino and Chinese in their previous grade levels were secured. Questionnaires were distributed and retrieved from the respondents. Then the oral proficiency tests were administered by different examiners for the English, Filipino and Chinese.

After tabulating and summarizing all the data, tabulation and analysis were done using the Statistical Package for the Social Sciences (SPSS).

\subsection{Data processing}

Descriptive statistics (percentages, means and standard deviations) were used to describe the personal profile, home and teacher factors. The chi-square was used to treat the data that refer to frequencies, while relationships were determined using the eta correlations. The contingency coefficient was applied to find out if any of the student, home and teacher factors could predict language performance. Multiple regression analysis was identified to test the statistical tool used.

\section{Results and discussions}

The data generated from the different instruments yielded interesting results relative to the study.

Table 1. Language Preference

\begin{tabular}{ccccccc}
\hline \multirow{2}{*}{$\begin{array}{c}\text { Order of } \\
\text { Preference }\end{array}$} & \multicolumn{2}{c}{ English } & \multicolumn{2}{c}{ Filipino } & \multicolumn{2}{c}{ Chinese } \\
\cline { 2 - 7 } & $\mathrm{N}$ & $\%$ & $\mathrm{~N}$ & $\%$ & $\mathrm{~N}$ & $\%$ \\
\hline 1st & 19 & 51.35 & 18 & 48.65 & 0 & 0 \\
2nd & 16 & 43.24 & 15 & 40.54 & 6 & 16.22 \\
3 3rd & 2 & 5.41 & 4 & 10.81 & 31 & 83.78 \\
& 37 & 100 & 37 & 100 & 37 & 100 \\
\hline
\end{tabular}

The results revealed that the students' most preferred language for communication is English, while Chinese is the least preferred one. On the other hand, the students' indifference over the Chinese language is due to the fact that most of them find it difficult to understand and speak the Chinese language.

\begin{tabular}{|c|c|c|c|c|c|c|c|c|c|c|c|c|}
\hline \multirow{2}{*}{$\begin{array}{c}\text { Order of } \\
\text { Preference }\end{array}$} & \multicolumn{2}{|c|}{ Computer } & \multicolumn{2}{|c|}{ TV } & \multicolumn{2}{|c|}{ Radio } & \multicolumn{2}{|c|}{ Newspaper } & \multicolumn{2}{|c|}{ Books } & \multicolumn{2}{|c|}{ Film } \\
\hline & $\mathrm{N}$ & $\%$ & $\mathrm{~N}$ & $\%$ & $\mathrm{~N}$ & $\%$ & $\mathrm{~N}$ & $\%$ & $\mathrm{~N}$ & $\%$ & $\mathrm{~N}$ & $\%$ \\
\hline $1^{\text {st }}$ & 25 & 67.57 & 5 & 13.51 & 0 & 0 & 1 & 2.7 & 2 & 5.41 & 4 & 10.81 \\
\hline $2^{\text {nd }}$ & 4 & 10.81 & 19 & 51.35 & 1 & 2.7 & 3 & 8.11 & 3 & 8.11 & 7 & 18.92 \\
\hline $3^{\text {rd }}$ & 2 & 5.41 & 4 & 10.81 & 4 & 10.81 & 5 & 13.51 & 9 & 24.32 & 13 & 35.14 \\
\hline $4^{\text {th }}$ & 4 & 10.81 & 5 & 13.51 & 7 & 18.92 & 3 & 8.11 & 13 & 35.14 & 5 & 13.51 \\
\hline $5^{\text {th }}$ & 1 & 2.7 & 4 & 10.81 & 9 & 24.32 & 14 & 37.84 & 6 & 16.22 & 3 & 8.11 \\
\hline $6^{\text {th }}$ & 2 & 5.41 & 0 & 0 & 16 & 43.24 & 11 & 29.73 & 4 & 10.81 & 5 & 13.51 \\
\hline Total & 37 & 100.00 & 37 & 100.00 & 37 & 100.00 & 37 & 100.00 & 37 & 100.00 & 37 & 100.00 \\
\hline
\end{tabular}

The computer turned out to be the most favoured among the types of media. It is followed by the television, film/movies/documentaries, books, and then newspapers. The radio is the least preferred type of media form. 
Table 3. Study Habits

\begin{tabular}{lll}
\hline Study Habits & N & $\%$ \\
\hline Very Good & 16 & 43.24 \\
Good & 21 & 56.76 \\
Total & 37 & 100 \\
\hline
\end{tabular}

This shows that more than half of the respondents have good study habits while the rest have very good study habits.

Table 4. Attitude Towards English, Filipino and Chinese

\begin{tabular}{ccccccc}
\hline Attitude & \multicolumn{2}{c}{ English } & \multicolumn{2}{c}{ Filipino } & \multicolumn{2}{c}{ Chinese } \\
\cline { 2 - 7 } & $\mathrm{N}$ & $\%$ & $\mathrm{~N}$ & $\%$ & $\mathrm{~N}$ & $\%$ \\
\hline Favorable & 22 & 59.46 & 13 & 35.14 & 3 & 8.11 \\
Non-Favorable & 15 & 40.54 & 24 & 64.86 & 34 & 91.89 \\
Total & 37 & 100 & 37 & 100 & 37 & 100 \\
\hline
\end{tabular}

Results show that more than half of the respondents have generally more positive and favourable attitude towards English. Ninety-two percent of the respondents show an unfavourable attitude towards Chinese.

Table 5. Motivational Orientation Towards English, Filipino and Chinese

\begin{tabular}{llllllll}
\hline Motivational & \multicolumn{2}{l}{ English } & \multicolumn{2}{l}{ Filipino } & \multicolumn{3}{c}{ Chinese } \\
\cline { 2 - 8 } Orientation & $\mathrm{N}$ & \multicolumn{2}{c}{$\%$} & $\mathrm{~N}$ & $\%$ & $\mathrm{~N}$ & $\%$ \\
\hline Instrumental & 20 & 54.05 & 20 & 54.05 & 19 & 51.35 \\
Integrative & 4 & 10.81 & 9 & 24.32 & 7 & 18.92 \\
Neither & 13 & 35.14 & 8 & 21.62 & 11 & 29.73 \\
Total & 37 & 100 & 37 & 100 & 37 & 100 \\
\hline
\end{tabular}

This shows that most of the respondents are instrumentally motivated towards learning the three languages. It shows that most of them believe in the practical value and the advantages that the language could give to them. Very few of them are motivated to learn the languages for the purpose of integrating with the culture of the people speaking the languages.

Table 6. Length of Exposure to the Languages

\begin{tabular}{ccccccc}
\hline \multirow{2}{*}{$\begin{array}{c}\text { Number of } \\
\text { Years }\end{array}$} & English & \multicolumn{3}{c}{ Filipino } & \multicolumn{3}{c}{ Chinese } \\
\cline { 2 - 7 } & $\mathrm{N}$ & $\%$ & $\mathrm{~N}$ & $\%$ & $\mathrm{~N}$ & $\%$ \\
\hline $0-4$ & 1 & 2.7 & 1 & 2.7 & 8 & 21.62 \\
5 - 9 years & 14 & 37.84 & 12 & 32.43 & 17 & 45.95 \\
10 and above & 22 & 59.46 & 24 & 64.86 & 12 & 32.43 \\
Total & 37 & 100 & 37 & 100 & 37 & 100 \\
Mean S.d. & 9.41 & & 9.61 & & 7.42 & \\
& 2.32 & & 2.13 & & 3.44 & \\
\hline
\end{tabular}


Table 6 presents the length of exposure to the three languages. It could be gleaned in the results that the average years of exposure to the language are as follows: 9.61 years in Filipino, 9.41 years in English and 7.42 years in Chinese.

\section{Table 7. Kind of School Enrolled In}

\begin{tabular}{lcc}
\hline School & N & $\%$ \\
\hline Private Chinese School & 28 & 75.68 \\
Private Non-Chinese School & 9 & 24.32 \\
Total & 37 & 100 \\
\hline
\end{tabular}

Table 7 shows that most of the respondents come from the private Chinese school and few of them belong to the private non-Chinese school.

Table 8. Language Spoken at Home

\begin{tabular}{lcc}
\hline Languages & $\mathrm{N}$ & $\%$ \\
\hline English, Filipino, Chinese, Waray, Others & 3 & 8.11 \\
English, Filipino, Chinese, Waray & 6 & 16.22 \\
English, Filipino Waray, Others & 4 & 10.81 \\
English, Filipino Waray & 11 & 29.73 \\
English, Chinese, Waray & 2 & 5.41 \\
English, Chinese, Others & 1 & 2.7 \\
English, Filipino, Others & 1 & 2.7 \\
English, Waray & 2 & 5.41 \\
English, Filipino & 2 & 5.41 \\
Chinese, Waray & 2 & 5.41 \\
Chinese, Filipino & 1 & 2.7 \\
English & 2 & 5.41 \\
Total & 37 & 100 \\
\hline
\end{tabular}

Table 8 presents the language/s spoken at home. The data shows that $76 \%$ of the respondents speak three to four languages at home whom we call the trilinguals or multilinguals. About $19 \%$ are bilinguals and 5\% are monolinguals. The most widely spoken language at home is English, followed by Waray (mother tongue), Filipino, and lastly, Chinese.

Table 9. Previous Final Ratings of Students in English, Filipino and Chinese

\begin{tabular}{cccc}
\hline Subject & N & Mean & S.D. \\
\hline English & 37 & 86.92 & 5 \\
Filipino & 37 & 86.76 & 4.6 \\
Chinese & 30 & 84.73 & 5.01 \\
\hline
\end{tabular}

In terms of the final ratings of the students, Table 9 shows that the mean ratings in English and Filipino are slightly higher compared to that of the Chinese subject. 
Table 10. Educational Materials at Home

\begin{tabular}{lrr}
\multicolumn{1}{c}{ Materials } & $\mathrm{N}$ & $\%$ \\
\hline Newspapers, Magazines, Books, Encyclopedia, Dictionary & 18 & 48.65 \\
Newspapers, Magazines, Books, Encyclopedia, Dictionary, Others & 41 & 21.62 \\
Newspapers, Magazines, Books, Dictionary & 5 & 13.51 \\
Magazines, Books, Encyclopedia, Dictionary & 2 & 5.41 \\
Magazines, Books, Dictionary & 1 & 2.7 \\
Magazines, Newspapers, Books & 1 & 2.7 \\
Newspapers, magazines, books, dictionary, others & 1 & 2.7 \\
Books & 1 & 2.7 \\
Total & 37 & 100 \\
\hline
\end{tabular}

In terms of educational facilities at home, most of the respondents' homes are equipped with computers with internet connections, television set, radio and VCD players. Hundred percent of the homes are equipped with television set, followed by computer sets with internet connections and then the VCD players. Only $83 \%$ of them had radio sets at home.

Table 10 shows that the books are the most commonly found educational material at home. It is followed by the magazines and dictionary. Only $76 \%$ of the homes had encyclopedias.

\begin{tabular}{lll}
\multicolumn{1}{c}{ Table 11. Ethnic Background } & & \\
\hline Ethnic Background & $\mathrm{N}$ & $\%$ \\
\hline Pure Chinese & 7 & 18.92 \\
Half-Chinese & 19 & 51.35 \\
Non-Chinese & 11 & 29.73 \\
Total & 37 & 100 \\
\hline
\end{tabular}

Table 11 presents the ethnic background of the participants wherein only $19 \%$ are pure-blooded Chinese, more than half are half-Chinese, while the rest non-Chinese.

Table 12. Attitude of Parents Towards English, Filipino and Chinese

\begin{tabular}{lrrrrrr}
\hline \multirow{2}{*}{ Attitude } & \multicolumn{2}{c}{ English } & \multicolumn{2}{c}{ Filipino } & \multicolumn{2}{c}{ Chinese } \\
\cline { 2 - 7 } & $\mathrm{N}$ & $\%$ & $\mathrm{~N}$ & $\%$ & $\mathrm{~N}$ & $\%$ \\
\hline Favorable & 24 & 64.86 & 10 & 27.03 & 5 & 13.51 \\
Unfavorable & 13 & 35.14 & 27 & 72.97 & 32 & 86.49 \\
Total & 37 & 100 & 37 & 100 & 37 & 100 \\
\hline
\end{tabular}

Among the parent respondents, more than half of them have a favorable attitude towards English over the Filipino language. On the other hand, most of the parent respondents have an unfavorable attitude towards the Chinese language. 
Table 13. Profile of Teachers

\begin{tabular}{|c|c|c|c|c|c|}
\hline $\begin{array}{l}\text { Subject } \\
\text { Teacher }\end{array}$ & Age & $\begin{array}{c}\text { Teaching } \\
\text { Experience } \\
\text { (years) }\end{array}$ & Degree & $\begin{array}{c}\text { with or } \\
\text { without } \\
\text { specialization }\end{array}$ & Highest Educational Attainment \\
\hline \multirow{3}{*}{$\begin{array}{l}\text { English } \\
\text { Teacher }\end{array}$} & 24 & 3 & BSED & with SPL & w/ more than 15 master's units \\
\hline & 35 & 14 & BEED & with SPL & CAR \\
\hline & 38 & 10 & BEED & with SPL & $\mathrm{w} /$ more than 15 master's units \\
\hline \multirow{3}{*}{$\begin{array}{l}\text { Filipino } \\
\text { Teacher }\end{array}$} & 24 & 3 & BSED & with SPL & Bachelor's degree \\
\hline & 28 & 3 & BEED & without & Bachelor's degree \\
\hline & 61 & 31 & BSED & with SPL & with more than 15 master's units \\
\hline \multirow[t]{3}{*}{ Chinese } & 24 & 1 & No answer & with SPL & CAR \\
\hline & 51 & 31 & BSC Mngt & with SPL & Bachelor's Degree \\
\hline & 59 & 35 & No Answer & With SPL & Bachelor's Degree \\
\hline
\end{tabular}

Table 13 presents the profile of teachers in terms of their age, number of years teaching experience, degree earned, specialization, and highest educational attainment. Results show that the English teachers are more advanced in terms of their educational attainment compared to the Filipino and Chinese teachers.

\begin{tabular}{|c|c|c|c|c|c|}
\hline Subject & Category & $\mathrm{N}$ & $\%$ & Classification & $\%$ \\
\hline \multirow[t]{6}{*}{ English } & A & 1 & 2.7 & Non-English Speaking & 2.7 \\
\hline & B & 12 & 32.43 & Average English Speaking & \multirow{3}{*}{70.27} \\
\hline & $\mathrm{C}$ & 9 & 24.32 & Average English Speaking & \\
\hline & $\mathrm{D}$ & 5 & 13.51 & Average English Speaking & \\
\hline & $\mathrm{E}$ & 7 & 18.92 & Fluent English Speaking & \multirow{2}{*}{27.03} \\
\hline & $\mathrm{F}$ & 3 & 8.11 & Fluent English Speaking & \\
\hline \multirow[t]{4}{*}{ Filipino } & A & 27 & 72.97 & Non-Filipino Speaking & 72.97 \\
\hline & B & 7 & 18.92 & Average Filipino Speaking & \multirow{3}{*}{27.03} \\
\hline & $\mathrm{C}$ & 1 & 2.7 & Average Filipino Speaking & \\
\hline & $\mathrm{D}$ & 2 & 5.41 & Average Filipino Speaking & \\
\hline Chinese & A & 37 & 100 & Non-Chinese Speaking & 100 \\
\hline
\end{tabular}

As regards to the oral language performance of the students in English, Table 14 shows that most of them are classified as Average English Speakers, a few are considered fluent speakers, and only one is NonEnglish Speaking. For the Filipino language, most of the respondents are considered as Non-Filipino speakers while a few are labelled as Limited Filipino speaking. Surprisingly, all respondents are classified as NonChinese speaking. 
Table 15. Correlation Between Student Factors and Home Factors

\begin{tabular}{|c|c|c|c|c|c|}
\hline Student Factors & Home Factors & $\begin{array}{l}\text { Chi- } \\
\text { Square } \\
\text { Value }\end{array}$ & df & Sig & Gamma \\
\hline & Attitude of parents towards & & & & \\
\hline Language Preference & Filipino & 5.392 & 1 & $.020 * *$ & $.744 * *$ \\
\hline Media Preference & Language spoken at home & 73.344 & 44 & $.004 * *$ & -0.35 \\
\hline Study Habits & Language spoken at home & 21.844 & 11 & $.026 * *$ & -0.036 \\
\hline Attitude Towards & Attitude of parents towards & & & & \\
\hline Filipino & Filipino & 7.309 & 1 & $.007 * *$ & 0.762 \\
\hline $\begin{array}{c}\text { Motivational orientation- } \\
\text { Filipino }\end{array}$ & $\begin{array}{l}\text { Attitude of parents towards } \\
\text { Chinese }\end{array}$ & 7.053 & 2 & $.029 * *$ & -0.2 \\
\hline $\begin{array}{c}\text { Motivational orientation- } \\
\text { Chinese }\end{array}$ & $\begin{array}{l}\text { Attitude of Parents towards } \\
\text { English }\end{array}$ & 10.409 & 2 & $.005 * *$ & 0.486 \\
\hline $\begin{array}{l}\text { Length of Exposure - } \\
\text { Chinese }\end{array}$ & Ethnic Background & 15.719 & 4 & $.003 * *$ & 0.836 \\
\hline $\begin{array}{l}\text { Kind of School Enrolled } \\
\text { in }\end{array}$ & Language spoken at home & 21.32 & 11 & $.030 * *$ & 0.148 \\
\hline Prior Grade in Filipino & Educational Facilities at Home & 7.339 & 6 & $.000 * *$ & 0.302 \\
\hline Prior Grade in Chinese & Language spoken at Home & 54.457 & 30 & $.004 * *$ & -0.412 \\
\hline
\end{tabular}

In terms of the correlation between student factors and home factors, the results below show that there is a high correlation between the following student and home factors: the language preference of the students and the attitude of parents towards Filipino; media preference of the students and the language spoken at home; student's attitude towards Filipino and that of the parents; the motivational orientation of the students and the attitude of parents towards Chinese; motivational orientation towards Chinese and the attitude of the parents towards English; the length of exposure to Chinese and the family's ethnic background; the kind of school enrolled in and the language spoken at home; the prior grade in Filipino and the educational facilities at home; and, the prior grades in Chinese and the language spoken at home.

Table 16. Correlation Between Student Factors and Oral Language Performance

\begin{tabular}{clcccc}
\hline \multirow{2}{*}{ Subject Student Factors } & Chi-Square Value & df & Sig & $\begin{array}{c}\text { Contingency } \\
\text { Coef }\end{array}$ \\
\hline \multirow{2}{*}{ English } & Language Preference & 5.962 & 2 & 0.51 \\
& Media Preference & 3.751 & 8 & 0.879 \\
& Study Habits & 1.741 & 2 & 0.419 \\
& Attitude towards English & 1.483 & 2 & 0.476 \\
& Motivational Orientation towards English & 6.486 & 4 & 0.166 \\
& Length of Exposure to the English Language & 1.107 & 4 & 0.893 & 0.544 \\
& Kind of School Enrolled In & 15.562 & 2 & $.000^{* *}$ & 0.171 \\
\hline Filipino & Final Ratings in English & 86.5 & 75 & 0.171 \\
& Language Preference & 2.501 & 1 & 0.114 \\
& Media Preference & 3.485 & 4 & 0.48 \\
& Study Habits & 1.568 & 1 & 0.211 \\
& Attitude towards Filipino & 7.309 & 1 & $.007 * *$ \\
& Motivational Orientation towards English & 1.817 & 2 & 0.403 \\
& Length of Exposure to the English Language & 1.507 & 2 & 0.471 \\
& Kind of School Enrolled In & 1.528 & 1 & 0.216 \\
& Final Ratings in English & 29.155 & 39 & 0.875 \\
\hline
\end{tabular}


It could be gleaned that the English language performance correlated with the kind of school enrolled in. Thus, good English speaking performance of students could be attributed to the kind of school they are enrolled in. And since Filipino oral language performance highly correlated with attitude towards the Filipino language, it could be inferred that the poor oral language performance of the students in Filipino could be attributed to their indifference towards the language.

Table 17. Correlation Between Student Factors and Teacher Factors

\begin{tabular}{|c|c|c|c|c|c|}
\hline Student Factors & Teacher Factors & $\begin{array}{c}\text { Chi-Square } \\
\text { Value }\end{array}$ & $\mathrm{df}$ & Sig & Gamma \\
\hline \multirow[t]{2}{*}{ Prior Grade in English } & Age & 21.1 & 8 & $.007 * *$ & -0.688 \\
\hline & Teaching Experience & 21.1 & 8 & $.007 * *$ & 0.688 \\
\hline \multirow[t]{2}{*}{ Kind of School Enrolled In } & Age & 37 & 2 & $.000 * *$ & -1.000 \\
\hline & Teaching Experience & 37 & 2 & $.000 * *$ & 1.000 \\
\hline \multirow[t]{2}{*}{ Language Performance } & Age & 12.233 & 2 & $.002 * *$ & 0.008 \\
\hline & Major/Specialization & 11.267 & 1 & $.001 * *$ & -1.000 \\
\hline Attitude Towards Filipino & Age & 6.311 & 2 & $.043 *$ & -0.337 \\
\hline \multirow[t]{4}{*}{ Kind of School Enrolled In } & Age & 37 & 2 & $.000 * *$ & -0.357 \\
\hline & Major/Specialization & 37 & 1 & $.000 * *$ & 1.000 \\
\hline & Educational Qualification & 12.554 & 1 & $.000 * *$ & 1.000 \\
\hline & Teaching Experience & 12.554 & 1 & $.000 * *$ & -1.000 \\
\hline \multirow[t]{3}{*}{ Language Performance } & Age & 12.233 & 2 & $.002 * *$ & 0.817 \\
\hline & Educational Qualification & 11.267 & 1 & $.001 * *$ & 1.000 \\
\hline & Teaching Experience & 12.233 & 2 & $.002 * *$ & 0.817 \\
\hline \multirow[t]{3}{*}{ Length of Exposure to Chinese } & Age & 19.7111 & 4 & $.001 * *$ & 0.493 \\
\hline & Educational Qualification & 15.43 & 2 & $.000 * *$ & 0.939 \\
\hline & Teaching Experience & 19.711 & 4 & $.001 * *$ & 0.493 \\
\hline \multirow[t]{2}{*}{ Kind of School Enrolled In } & Educational Qualification & 37 & 1 & $.000 * *$ & 1.000 \\
\hline & Teaching Experience & 37 & 2 & $.000 * *$ & 1.000 \\
\hline
\end{tabular}

In terms of the correlation of student factors and English teacher factors, the students' language preference highly correlated with the teachers' age, educational qualification and teaching experience. Prior grade in English correlated with the teachers' age and the teaching experience; while, the kind of enrolled in highly correlated with the teachers' age and teaching experience.

As for the Filipino teacher factors and student factors, the students' language preference for the Filipino language highly correlated with the Filipino teachers' age and major/specialization. The students' attitude towards Filipino showed weak, but significant correlation. The students' preference for the Filipino language highly correlated with all the student factors.

The language preference for and the length of exposure to Chinese as well as the kind of school enrolled in highly correlated with the age, educational attainment, and teaching experience of the Chinese teachers. 
Table 18. Correlation between Home Factors and Oral Language Performance

\begin{tabular}{llccc}
\hline \multirow{2}{*}{ Subject } & \multicolumn{1}{c}{ Home Factors } & $\begin{array}{c}\text { Chi-Square } \\
\text { Value }\end{array}$ & df & Sig \\
\hline \multirow{2}{*}{ English } & Language Spoke at Home & 2.847 & 22 & 0.937 \\
& Educational Facilities at Home & 9.33 & 6 & 0.156 \\
& Educational Materials at Home & 27.465 & 14 & 0.653 \\
& Ethnic Background & 2.06 & 4 & 0.725 \\
& Attitude towards English & 2.167 & 2 & 0.338 \\
\hline \multirow{2}{*}{ Filipino } & Language Spoke at Home & 10.726 & 11 & 0.466 \\
& Educational Facilities at Home & 3.102 & 3 & 0.376 \\
& Educational Materials at Home & 2.465 & 7 & 0.93 \\
& Ethnic Background & 0.776 & 2 & 0.678 \\
& Attitude towards English & 1.169 & 1 & 0.28 \\
\hline
\end{tabular}

The results show that none of the home factors correlated with language performance, thus, the home factors have no bearing with the oral language performance of the students in English and Filipino.

Table 19. Relationship between Teacher Factors and Oral Language Performance

\begin{tabular}{clcccc}
\hline \multirow{2}{*}{ Subject } & \multicolumn{1}{c}{ Teacher Factors } & $\begin{array}{c}\text { Chi-Square } \\
\text { Value }\end{array}$ & df & Sig & $\begin{array}{c}\text { Contingency } \\
\text { Coef }\end{array}$ \\
\hline \multirow{2}{*}{ English } & $\begin{array}{l}\text { Age of Subject Teacher } \\
\text { Major/Specialization }\end{array}$ & $\mathbf{1 6 . 2 0 8}$ & $\mathbf{4}$ & $\mathbf{. 0 0 3} * *$ & $\mathbf{0 . 5 5 2}$ \\
& Educational Qualification & 2.023 & 2 & 0.364 \\
& Experience in Teaching & $\mathbf{1 6 . 2 0 8}$ & $\mathbf{4}$ & $\mathbf{. 0 0 3} * *$ & $\mathbf{0 . 5 5 2}$ \\
\hline Filipino & Age of Subject Teacher & 1.537 & 2 & 0.464 \\
& Major/Specialization & 1.528 & 1 & 0.216 \\
& Educational Qualification & 0.41 & 1 & 0.522 \\
& Experience in Teaching & 0.41 & 1 & 0.522 \\
\hline
\end{tabular}

The results show that age and the experience of the subject teacher highly correlates with the oral proficiency of the students. Thus, students under younger teachers has better language performance than those who are taught by older teachers.

Table 20. Significant Predictor of English Language Performance

\begin{tabular}{cccccc}
\hline \multicolumn{9}{c}{ ANOVA } \\
\hline Model & Sum of Squares & df & Mean Square & F & Sig. \\
\hline Regression & 392.900 & 1 & 392.9 & 27.077 & 0.000 \\
Residual & 507.857 & 35 & 14.51 & & \\
Total & 900.757 & 36 & & & \\
\hline
\end{tabular}

\footnotetext{
a. Predictor: (Constant), Kind of School

b. Dependent Variable: Performance in

English
} 
Coefficients

\begin{tabular}{|c|c|c|c|c|c|}
\hline \multirow[t]{2}{*}{ Model } & \multicolumn{2}{|c|}{ Unstandardized Coefficients } & \multirow{2}{*}{$\begin{array}{c}\begin{array}{c}\text { Standardized } \\
\text { Coefficients }\end{array} \\
\text { Beta }\end{array}$} & \multirow[t]{2}{*}{$\mathrm{T}$} & \multirow[t]{2}{*}{ Sig. } \\
\hline & B & Std. Error & & & \\
\hline 1 (Constant) & 85.071 & 0.72 & & 118.175 & 0.000 \\
\hline Kind of School & 7.595 & 1.46 & 0.66 & 5.204 & 0 \\
\hline
\end{tabular}

Table 21 presents the significant predictor of English language performance. The kind of school enrolled in is a significant predictor of oral language performance.

\section{Recommendations}

5.1 English is the most preferred language for communication, followed by Filipino, then Chinese, hence language teachers are encouraged to provide more interesting and engaging speaking activities in their language classes in order for the students to find ease and comfort in the use of the target languages for formal and informal communication. Since the most favoured type of media is the computer, closely followed by television, films, books, then newspapers, the use of multimedia in the instruction is suggested in order to provide much input in language learning.

5.2 School and home partnership needs to be enhanced. Involving the parents to guide and support their children in their school work is encouraged. Speaking different languages that may help provide input is encouraged. Classrooms likewise need to be equipped with varied learning facilities and materials to enhance learning in school. The provision for mini-learning centers and learning resource centers in the classrooms or in the school would be a great help for the students. Students should be given opportunities to utilize these materials and facilities such as computers, encyclopedias for meaningful language learning activities.

5.3 Results revealed that the teachers teaching English and Filipino finished degrees related to teaching. On the other hand, teachers teaching in Chinese were not. While most of the teachers are specializers in the subjects they are teaching, English teachers had higher educational attainment since most of them had units in their graduate studies while those teaching in the Filipino were mostly bachelor's degree holders only. Administrators should look into the profile of the teachers and check on the alignment of teaching assignment and the teachers' degrees; likewise, teacher need professional advancement for them to become more competent teachers in the field.

5.4 The oral language performance of students in English is Average Speaking Level. The language teacher in English could provide more speaking activities so that students could attain fluency in the language. Since most of the students are labelled as non-Filipino speaking, Filipino language teachers should provide more activities and opportunities wherein students will be speak the language. Speaking the language should likewise be enforced during HEKASI, EPP, and Edukasyong Pagpapahalaga. On the other hand, since hundred percent of the respondents were labelled as Non-Chinese Speaking, there is dire need to revisit the Chinese curriculum and look into the subjects for Chinese communication. Functional communication needs to be emphasized rather than simply rote memorization of Chinese terms and expressions.

5.5 Based on the results, performance of the students in school are greatly affected by a number of home factors, hence, parents' involvement in the giving support and guidance on the students' school work. Parent-teacher conferences could serve as avenue to keep them posted of the performance of their children in school. Since students were mostly affected by the language spoken at home as well as the parent's attitude towards the languages, informing them about the beneficial effects of using these languages at home as well as exposing them to different reading materials would prove helpful. 
Based on the results that student factors were affected by most of the teacher factors, the language teachers should be specialized in the subjects since they are considered experts in their fields in terms of the appropriate strategies, techniques and methods in teaching the different subject areas. Teachers need to continue updating themselves to improve their teaching performance by attending in-service trainings and workshops and foregoing further studies related to their course. The language teachers should serve as role models in the use of the English, Filipino and/or Chinese in communicating with the students during formal and informal conversations in order to encourage the students to speak the language.

5.6 The results revealed that there is a correlation of some student factors (i.e. school enrolled in and attitude towards Filipino language) and oral language performance. Those students enrolled in NonChinese school perform better in English, those in Chinese school perform better in Filipino, however both have same performance in Chinese. A need to revisit the curricular offerings of the school in both English and Chinese Studies. Bench marking in some schools with high performance in Language teaching would prove helpful.

5.7 Since the teacher factors such as the age and the teaching experiences found to be highly correlated with oral language performance, and that students under younger teachers had better language performance than those under older ones. School administrators should give opportunities for the teachers who have been in the service for more than fifteen years to undergo in-service trainings in order to keep them updated of the current trends and innovations in the educational setting.

5.8 Since none of the home factors correlated with language performance, much effort on the improvement of language performance of the students would lie heavily on the student and teacher factors. Hence, the school needs to closely evaluate, provide quality instruction and monitor performance of the students in order for them to ensure language proficiency. Intensified campaign on the use of the three languages as media of instruction would be a great help.

5.9 The kind of school enrolled in is a significant predictor of oral language performance. Hence, the schools should consider specializing on particular languages to be developed in a particular school. Capitalizing on the school programs and activities that gear towards the attainment of the school goals in terms of language to be developed should be emphasized.

\section{Acknowledgements}

The researcher would like to thank the approval of the school heads and the cooperation of the students of the three private institutions for the successful conduct of the study.

\section{References}

Charkova K. (2004). Early foreign language education and metalinguistic development: A study of monolingual, bilingual and trilingual children on noun definition tasks. Annual Review of Language Acquisition 3(1):51-88. Doi:10.1075/arla.3.04cha.

Education in a multilingual world (2003). UNESCO, Paris.

Harris, R.J., McGee Nelson, E.M. (1992). Bilingualism: Not the exception any more. Elsevier Science Publishers https://www.researchgate.net/publication/229265404_Bilingualism_Not_the_Exception_Any_More

Herbert F. W. Stahlke. (2002). Language, 78(4), 776-778. Retrieved February 5, 2021, from King, L. (2018). The impact of multilingualism on global education and language learning. Cambridge Assessment English Perspectives retrieved from https://www.cambridgeenglish.org/Images/539682-perspectivesimpact-on-multilingualism.pdf Retrieved from http://www.jstor.org/stable/3086712 
Kulsariyeva, A., Iskakova, A., Tajiyeva, M. (2017). Trilingual education: An effective way of providing inclusion. European Scientific Journal. Special Ed. ISSN: 1857 - 7431.

Lugoloobi-Nalunga (2013). Teaching and learning English in a multilingual classroom: A study of code switching in an EFL/ESL teaching/learning situation. Retrieved from https://www.divaportal.org/smash/get/diva2:704152/FULLTEXT01.pdf

Guzman, W., De Vera, P. (n.d.) English language performance and difficulties of students in the mother tongue -based (MTB) Medium of Instruction. Pangasinan State University - School of Advance Studies. Retrieved from https://files.eric.ed.gov/fulltext/EJ1247323.pdf

Ryu, M. (2019). Mixing languages for Science learning and participation: An examination of Korean-English bilingual learners in an after-school science-learning programme. International Journal of Science Education., v41 n10 p1303-1323. ISSN-0950-0693.

Schumann, J. (1986). Research on acculturation model for L2 acquisition. Journal of Multilingual and Multicultural Development, 7, 379-397.

Tupaz, R. (2016). Bilingual and Mother Tongue-based multilingual education in the Philippines. (pp. 1-13) National Institute of Education (NIE), Singapore.

Webb, K., Kembo-Sure, eds. African Voices: An Introduction to the Languages and Linguistics of Africa, Oxford University Press, Southern Africa, 2000 